\title{
Doença e Tempo
}

\section{Illness and Time}

\author{
Fernando S. P. Telles ${ }^{1}$ \\ Henrique Antoun ${ }^{2}$ \\ James B. Arêas $^{3}$
}

\section{TELLES, F. S. P.; ANTOUN, H. \& ARÊAS, J. B. Illness and Time. Cad. Saúde Públ., Rio de} Janeiro, 9 (3): 309-315, jul/sep, 1993.

This paper attempts to establish the appropriateness of the question: "Does it make sense to conceive of illness as a phenomenon that transcends categories of representation?"

A correspondence between the phenomena of representation and spatialization can be identified. Representation in this sense is the definition of a pathway that allows for chronological reference, in which a certain phenomenon is presented.

We consider the paradigm that defines the Anatomical-Clinical domain and Epidemiology as a form of representation or spatialization of illness.

We conclude that it is possible to approach the process called "becoming ill", which trancends anatomical-clinical and epidemiological representation, provided that we admit the possibility of constructing knowledge beyond space, i.e., in non-chronological time.

Key words: Time Factors; Disease; Medical Philosophy

\section{INTRODUÇÃO}

O presente texto aborda a diferença de natureza que pode haver entre a doença concebida como um fenômeno que se define num certo espaço e a sua possibilidade não-espacializada. Chamaremos representação de doença às várias configurações espaciais por ela tomada.

Nos últimos dois séculos, a enfermidade se configurou ou tomou formas distintas nos seus espaços possíveis, o que tornou viável o surgimento da Anátomo-Clínica (Foucault, 1987), nosso atual paradigma de doença. Ao nos utilizarmos do exemplo de Foucault, pretendemos demostrar a espacialização como um fenômeno possível, mas não exatamente neces-

\footnotetext{
${ }^{I}$ Instituto Fernandes Figueira, Fundação Oswaldo Cruz. Av. Rui Barbosa 716. Rio de Janeiro, RJ, 22250-020, Brasil.

${ }^{2}$ Departamento de Artes da Pontifícia Universidade Católica do Rio de Janeiro. Rua Marquês de São Vicente 266. Rio de Janeiro, RJ, 22451-040, Brasil.

${ }^{3}$ Departamento de Filosofia da Pontifícia Universidade Católica do Rio de Janeiro. Rua Marquês de São Vicente 266. Rio de Janeiro, RJ, 22451-040, Brasil.
}

sário para a doença se apresentar. Esta é a nossa hipótese, ou seja, a possibilidade de se poder pensar a enfermidade como algo que possa tomar realidade além dos espaços, isto é, no tempo.

Trata-se de um ensaio para o qual buscamos auxílio na Filosofia, através de pensadores como Deleuze, Félix Guattari e Henri Bergson.

Sabemos não ser banal a tarefa de estudar representações, seja lá do que se queira. Nossa pesquisa, entretanto, tomará outro rumo, qual seja o de colocar em questão a própria representação que, como se verá, será chamada por nós de espacialização.

Após destacarmos as formas de espacialização de doença em "O Nascimento da Clínica", tentaremos abordar o tema da espacialização propriamente dita para, ao final, formularmos nossa tese, que tentará demonstrar a propriedade de se pensar a doença no tempo.

Esta idéia, vinda de um médico especialista em Terapia Intensiva Pediátrica, surge a partir do momento em que ele vê nos limites dos pressupostos científicos que definem doença, uma certa deficiência oriunda de sua própria 
natureza científica, e não exatamente de um problema metodológico. Não se trata, portanto, de um estudo epistemológico. Não se quer trocar um paradigma por outro. Não se trata de pensar um certo fenômeno - doença - para o qual já são necessários novos postulados científicos. Buscamos, ao contrário, demonstrar $\mathrm{o}$ paralelismo que se forma entre a necessidade de se espacializar ou representar e a própria natureza científica dos caminhos que se utilizam para tal. Chamamos a atenção para outra forma de "saber" que se diferencia da ciência por se firmar em outra natureza.

Tentaremos problematizar o fenômeno da doença. Problematizar, para nós, será algo que, em sua construção, excederá a possibilidade dos pressupostos científicos (Deleuze, 1988a). Sabe-se, por exemplo, que a Matemática excede em muito a sua apresentação numérica. Como se pode apreender a existência do infinito dentro de um intervalo finito de números, como entre um e dois? Trata-se de poder pensar o paradoxo que, em nossa hipótese, não se espacializa e, ao contrário, se afirma em problemas que, num certo sentido, não se submetem às categorias da representação.

Tal será nossa aventura, a de poder afirmar a doença através de seus paradoxos, ou melhor, afirmar a propriedade desta questão.

\section{DOENÇA E ESPAÇO}

A medicina da época Clássica passou a constituir formas de configuração das enfermidades, a partir de um certo atributo que passou a ser sua marca. Foucault chama "saber histórico" a tal fenômeno que se constitui num certo privilegiamento do olhar como instrumento necessário ao entendimento da enfermidade (Foucault, 1987). A doença passa, então, a se configurar em planos ou patamares acessíveis a uma certa descrição, ou melhor, passa-se a poder enunciar em termos de doença tudo aquilo que se preste a uma configuração inequívoca aos diversos olhares. Este "saber histórico" que funda a "genealogia do olhar" como forma de se legitimar algo que se diz, sucede no tempo o chamado "saber filosófico", que descrevia a enfermidade na ordem das causalidades. Na verdade, com o "saber histórico" se descreve tudo aquilo que se pode configurar, não havendo, em princípio, a preocupação causal ou temporal do "saber filosófico". Um processo inflamatório passa a ser definido pelos fenômenos acessíveis ao olhar - calor, rubor, tumor - não importando muito a sua relação temporal (Foucault, 1987). Não é que os médicos da época Clássica tenham abandonado a noção de causalidade, mas, curiosamente, nesta nova forma de saber o tempo passará a impor, como se verá adiante, o aparecimento de novos planos de configuração e que passarão a manter entre si uma certa relação causal.

Foucault destaca, então, nesta sequiência, a "Medicina das Espécies" e a "Clínica". A "Clínica" tomará significados distintos nas chamadas "Protoclínica", "Clínica do final do século XVIII" e, finalmente, a "Anátomo-Clínica” (Foucault, 1987).

$\mathrm{Na}$ "Medicina das Espécies" as doenças eram agrupadas por gêneros e espécies, em quadro classificatório de modelo "aristotélico". Verdadeiro plano teórico em que um suposto "ser" da doença se dizia nas várias espécies subordinadas. $\mathrm{O}$ ato de dizer de uma doença ("a doença tal é....") fazia seu gênero tomar realidade, através da predicação, ou seja, o próprio termo específico. Nesta classificação, a doença era um "ser" virtual que tomava realidade após a especificação. A realidade do "ser" da doença só era possível, então, nas estampas deste espaço classificatório. Foucault chama a isto "espacialização primária" da doença (Foucault, 1987). A doença admitia, então, existência própria e independente em seu espaço. A consequiência imediata disto é que sua manifestação nos corpos tomava o aspecto de uma refração de sua essência. De fato, o doente era considerado um acidente que, embora fosse necessário ao aparecimento da doença, deturpava sua forma original. Os sintomas traduziam, então, a manifestação das espécies nosológicas no corpo humano. Era necessário abstrair o doente e seus sintomas para se chegar à essência nosológica em seu "espaço primário.". A configuração da doença no corpo foi chamada por Foucault "espacialização secundária da doença" (Foucault, 1987). Um terceiro tipo da espacialização, terciário ou das Epidemias, segundo Foucault, surge também nesta época. Com o advento da formação das indústrias e de uma economia de 
mercado, surgem grandes agrupamentos humanos nas cidades. Tais aglomerados passarão a ser o palco ou a tela que tornará acessível ao olhar uma nova série de fenômenos que definirão as epidemias. Curioso espaço de configuração do mal que, mais do que criar novas formas de visibilidade irá, como veremos adiante, colocar em questão as duas formas anteriores de espacialização.

Talvez a contradição entre o que a epidemia fazia ver e aquilo que era dito no plano teórico do espaço primário, tenha sido responsável pelo enfraquecimento irreversível do sistema. É que com as epidemias tem-se a variável tempo introduzida abruptamente no paradigma da "Medicina das Espécies". Tal introdução impôs mudanças tão radicais ao sistema que tornou inviável sua própria existência. Mesmo sem o conhecimento microbiológico causal, uma relação causa-efeito se estabelecia e os aglomerados humanos passavam a tomar parte da configuração da "Peste" ou da "Epidemia de Catarro" (Foucault, 1987). Tal sistematização de doença, bem como as medidas corretivas geradas pela "polícia médica", não encontravam justificativas teóricas nos espaços primário e secundário e, no entanto, eram eficientes. A nosografia acadêmica passa, então, a ser foco de críticas por parte de órgãos governamentais (falamos do período pós-Revolução Francesa) (Foucault, 1987).

Um novo tipo de sistematização nosográfica se faz necessário, sem o que a própria Academia de Medicina passa a correr risco de implosão. A Clínica tem agora solo fértil para sua possibilidade de surgimento.

Surge, no século XVIII, a chamada "Protoclínica". Na busca de se integrar o que se via nas epidemias a algo que pudesse ser dito, alguma coisa qualitativamente diferente é introduzida no conhecimento médico. Dentro de uma nova lógica, o doente passa a ser objeto de ensino, através dos exemplos nosológicos que podem ser extraídos de sua enfermidade. Os hospitais de ensino passam a selecionar pacientes para a internação, não mais como casos a serem desvelados, mas como exemplos vivos de doença. Sem dúvida, trata-se de uma nova sistematização, mas ainda pouco capaz de definir um novo espaço nosográfico (Foucault, 1987).
No final do século XVIII, surge uma outra possibilidade de sistematização. Dois tipos de saberes contribuem para o desenvolvimento desta nova clínica, quais sejam: a Lingüística e o Cálculo Probabilístico. Passa-se a ver no corpo humano o local de sintomas que, através da teoria lingüística, passariam a ser "lidos" como signos que seriam a própria doença "encarnada" no corpo (Foucault, 1987). Já se tem aí uma mudança bem mais radical. Agora a doença já não é mais uma essência que se refrata no corpo, através de seus sintomas. A ela é o próprio sintoma cuja espacialização se sistematiza nos signos. Espaço lingüístico, cuja existência tende a apagar a nosografia das "Espécies", ou seja, da doença como uma essência e o doente como um mero acidente. $\mathrm{O}$ cálculo probabilístico, por outro lado, tende a legitimar o sistema "sinal-signo", tornando evidente, pelo estudo de frequiências, a probabilidade de erro da correlação dos fenômenos. Este último saber não chegou a ser bem utilizado na época, mais por não ter sido bem aplicado do que por seu conteúdo teórico. Por um lado, passou-se a dar tratamento matemático a fenômenos de ordem qualitativa (sintomas); por outro lado, ainda não havia, na época, doentes hospitalizados em número suficiente para a amostra estatística. No que diz respeito à lógica lingüística, a mesma ainda não se estabelecia como sistema teórico acabado. Tais fatos, em pouco tempo, transformaram os pacientes em fonte de informações confusas. Conseqüentemente não se criava, ainda, um espaço de representações que substituísse, de forma efetiva, o da "Medicina das Espécies". Mesmo assim, pode-se dizer que a clínica do final do século XVIII criou dois tipos de representação para doença: um linguiístico e outro matemático.

Ainda no final do século XVIII e durante o século XIX, surge outra mudança na estrutura do conhecimento médico, a mais radical e que viabilizará uma integração coerente entre o visível e o dizível das doenças. Trata-se da "Anátomo-Clínica".

Bichat em seu Traité des Membranes, vai dar um novo sentido, ou melhor, uma nova utilidade à dissecação de cadáveres (Bichat apuc Foucault, 1987). A individualização dos tecidos como sítios de eventos mórbidos, passará a dar aos órgãos a transparência necessária ao olhar 
do clínico. Isto só será possível porque tais membranas, delgadas estruturas imanentes da própria morbidez, melhor se adaptarão à lógica lingüística do sistema anterior. $\mathrm{O}$ olho do clínico passa a ter o "poder dos raios- $X$ " neste novo espaço, agora volumétrico e de órgãos transparentes.

Não há mais lugar para a "Medicina das Espécies", cujo fim se estabelece pouco tempo depois, com Broussais, que desenvolve a noção de foco patológico inicial e disseminação sistêmica, a partir deste foco de origem (Foucault, 1987).

O volume Anátomo-Clínico define um novo espaço de representações. A partir daí, as essências nosológicas perdem seu sentido e, com elas, o próprio termo - doença - também o perde. Se antes saúde e doença se opunham, agora a sanidade se definirá por um conceito de normalidade em oposição a tudo o que for patológico. Antes, saúde $\mathrm{x}$ doença; agora, normal x patológico. $\mathrm{O}$ corpo humano passa a ter uma linguagem própria, cujos signos são apreendidos num sistema lógico que correlaciona eventos tissulares à teoria da linguagem e que se constitui no próprio evento mórbido encarnado, ou seja, a patologia.

O problema que ora se levanta é o de saber se o fato de o sistema patológico ter definitivamente abolido a necessidade das essências nosológicas, aboliu, também, a possibilidade de a doença se dizer de outras formas. Acreditamos que não, mas sem querer buscar tipos alternativos de representação. Não queremos dissertar sobre a doença como um fenômeno que se representa na Anátomo-Clínica mas que, também, pode fazê-lo em outro sistema, talvez até mais eficiente. Não acreditamos, em nossa linha teórica, nos fenômenos "em essência" e que precisam ser apreendidos por um ou por outro sistema teórico. Ao contrário, acreditamos que ao se impor a um acontecimento qualquer (doença, por exemplo) um espaço de representações, isto não é feito sem que se transforme o acontecimento naquilo que se confunde com o próprio sistema de representações. Um doente ou mesmo um médico, em seus respectivos papéis cotidianos, não abandona o termo "doença". O doente diz "passar mal"; o médico indaga-lhe "o que houve?". Achamos que isto demonstra que algo excede a representação patológica. Vamos tentar buscar este excesso fora dos espaços da representação, isto é, no tempo.

\section{DOENÇA E TEMPO}

Em nossa linha teórica, a diferença entre um "acontecimento" e "aquilo que acontece" é de natureza. $\mathrm{O}$ acontecimento é da ordem do tempo, mas de um tempo livre de numeração, não cronológico. É o próprio devir. Sua multiplicidade só pode ser apreendida no seio deste tempo sem referenciais. O tempo que se mede é de outra natureza; é cronológico. O acontecimento referido ao tempo cronológico passa a ser apenas aquilo que acontece (Deleuze, 1974). É este o sentido que buscamos demonstrar existir no fenômeno da representação. Não se traça uma linha numérica no tempo sem que, com isto, se retire do acontecimento sua possibilidade múltipla. $\mathrm{O}$ acontecimento é o próprio movimento que, ao ser vinculado a uma numeração temporal se transforma em simples trajetória. A trajetória é o espaço daquilo que se representa. Representar é tornar presente o que se foi e que não pode mais ser em um tempo linear e cronológico. Já no tempo não cronológico não se representa, porque nele não há realidade objetiva nas diferenças entre passado, presente e futuro. É o próprio paradoxo do tempo. O acontecimento é o lugar do paradoxo; aquilo que acontece é a própria represen-tação espacializada.

Se pudéssemos compreender por quais motivos os seres conscientes espacializam seu universo, talvez entendêssemos melhor a natureza daquilo que se espacializa. Henri Bergson, em "Matéria e Memória", estuda bem as relações entre as séries espacial e temporal e nos faz ver que mundos diferentes se formam, quando tomamos o movimento ora vinculado a uma cronologia, ou ao contrário, em seu próprio tempo, isto é, em sua duração (Bergson, 1990).

Se imaginarmos a matéria com seus incontáveis movimentos, com todas as possibilidades de encontros e agenciamentos entre suas porções, talvez nos pareça ser um verdadeiro milagre o surgimento de indivíduos, a partir de tais movimentos. É que para nós, seres conscientes, as coisas ou corpos já nos são tão 
familiares que suas respectivas estabilidades nos dão a noção de um princípio de ordem universal. Para um certo átomo de carbono em seus vários encontros com outros átomos durante a formação e quebra de certas moléculas, nada muda, seja em que ponto ele esteja nas reações químicas. É que em todas estas repetições que a atividade da matéria proporciona não há um tempo fundado para aquilo que se movimenta; no caso, o próprio átomo de carbono. Acontece que aquilo que repete pode tomar um certo sentido para um outro. Este outro que pode não ser, necessariamente, um ser consciente terá, por outro lado, papel decisivo na fundação do tempo. Se as incontáveis repetições da matéria vividas pelo tal átomo de carbono fizerem sentido, em seu conjunto, a um outro, é porque para este outro tais movimentos admitem uma certa duração. Uma molécula de glicose pode se formar justamente por ter sido estabelecido um sentido em certos movimentos da matéria que repete. Este sentido se forma, a partir desta primeira síntese do tempo. Chama-se hábito a esta primeira síntese temporal (Deleuze, 1988a). A molécula de glicose, agora como sentido contraído passa a ser elemento de repetição que pode, através de composições com outras moléculas, fazer sentido para um outro. Este outro pode ser uma molécula maior que, por sua vez, iniciará repetições até que, de forma sucessiva, ter-se-á um organismo formado. Os organismos, devido às múltiplas contrações de seus hábitos, terão a capacidade de perseverar, ou seja, de se tornarem estáveis.

A matéria repete e, a partir daí, sentidos podem ser estabelecidos. São oriundos de uma síntese temporal, ou melhor, são o próprio tempo que institue na matéria algo de novo, isto é, uma Diferença. Gilles Deleuze, em "Diferença e Repetição" diz que nós nos contituímos, a partir de incontáveis hábitos muito antes de adquirirmos uma consciência (Deleuze, 1988a). Os Estóicos estabeleciam uma diferença entre o tempo dos corpos e o tempo dos sentidos possíveis, oriundos da junção ou separação dos corpos. Diziam que os corpos ao se conjugarem formavam coisas ou estados de coisas e que se definiam em um presente finito (Deleuze, 1974). Vários presentes conjugar-se-iam, como conseqüência dos agenciamentos possíveis de toda a matéria do universo. De tais conjugações formar-se-iam sentidos ou efeitos incorporais e que pertenceriam aos tempos passado e futuro. Em nosso exemplo do átomo de carbono, as várias moléculas formadas pertenceriam ao presente devido às suas repetições, mas seriam também passado e futuro por serem efeitos da própria contração do tempo. Tem-se aí um paradoxo, ou seja, o de se afirmar algo como sendo simultaneamente tempo e matéria.

Outros pensadores, vislumbrando o tempo a partir dos Estóicos, vão mais além e dizem ser o sentido a própria realidade do Universo. Se por um lado a matéria repete, por outro, são os sentidos gerados que nos dão sua realidade, numa síntese temporal não-cronológica que, muito mais que efeito das repetições desta matéria, são sua própria realidade. Multiplicidade livre, a partir dos movimentos da matéria, tal é a lógica dos sentidos infinitos que se constituem na própria Diferença. Assim é a metáfora das cartas de baralho de Lewis Carroll em "Alice no País das Maravilhas". Seres sem espessura e somente possuidores de sentidos "lidos" em suas superfícies. A lógica deste tempo aberto, sem limites e "encarnador" do próprio sentido, se dissipa quando acrescentamos uma consciência reflexiva aos movimentos da matéria. Nossa consciência, devido às necessidades práticas da existência tende a generalizar as séries formadas pelas repetições da matéria em um passado de reflexão que cria uma seta temporal apontada para um futuro, que agora já pode ser elaborado, previsto (Deleuze, 1988a). O tempo, antes sem limites, toma agora a forma de uma linha onde passado, presente e futuro admitem uma cronologia. Todo o sentido que se extrai, a partir da matéria que repete, encontra-se no passado reflexivo e que, agora, deve ser encenado no presente das re-presentações que se dirige a um futuro já imaginado. É isto que chamaos espaço das representações. $O$ sentido que já se encontra no passado volta ao instante presente, através da generalização reflexiva. Acontece que o instante presente, por menor que venha a ser, dura algum tempo e já se torna passado no simples momento em que pensamos nele. Tem-se, então, um outro paradoxo. O instante presente é inapreensível e, para tomar realidade, é preciso que seja encenado, criando-se para o espetáculo cênico um espaço para represen- 
tações. Henri Bergson chama a atenção para o fato de a espacialização ser um fenômeno necessário à percepção dos seres. Por outro lado, afirma que o conhecimento também pode se dar, a partir da apreensão dos sentidos que duram e que são o próprio tempo não cronológico (Bergson, 1990).

Em nossa pesquisa julgamos ser a AnátomoClínica um tipo de espacialização ou representação de doença. Julgamos que, com isso, o próprio devir, ou seja, a própria duração, um certo adoecer, escapa e em grandes proporções ao espaço patológico. A própria Epidemiologia já percebe este excesso, embora contrua um outro espaço para representar doença; os espaços sociais dos fatores de risco.

Queremos poder conceber a doença em sua singularidade; um adoecer como alteração qualitativa e não como uma trajetória que se finca na lesão patológica.

\section{CONCLUSÃO}

Para Gilles Deleuze e Félix Guattari, a filosofia tem por objeto "criar conceitos". Para eles o "conceito filosófico" é a própria "materialização" do Acontecimento, ou seja, seu próprio sentido (Deleuze \& Guattari, 1992). É preciso ser dotado de uma certa habilidade para se perceber, a partir dos fenômenos, os conceitos possíveis que podem suscitar. A Ciência, ao estabelecer um plano de referência nos acontecimentos, os retira do tempo e os coloca no espaço. Como vimos, não se espacializa sem se representar. Não se quer criticar a atividade científica e sim questionar se, mesmo nas atividades práticas da existência, o conhecimento científico nos basta. Julgamos que, se a patologia dos corpos e da sociedade é atributo de diversas Ciências, talvez haja um "adoecer", cujos conceitos estão por ser concebidos. Não nos parecem suficientes outras formas de representação, ao contrário, nos interessa perceber os sentidos possíveis deste "adoecer".

Uma criança desnutrida e com Tuberculose disseminada não pode ter, para nós, sua doença definida pela série de eventos patológicos e epidemiológicos do nosso paradigma de doença. Que série de agenciamentos, ou melhor, que tipo de Acontecimento se deu e que dele só percebemos os espaços clínico e epidemiológico? Será eficiente este paradigma? E se não for, será que nos faltam formas melhores de se espacializar? E a AIDS? Que acontecimento, que singularidade se deu e que só foi conhecida como AIDS?

Esta pesquisa foi elaborada como um ensaio para se verificar a propriedade de se poder conceber doença como algo não espacializado e constitui-se no tema de dissertação do "Mestrado em Saúde da Criança" do Instituto Fernandes Figueira, no ano de 1992, realizada por um dos autores deste artigo. Pretendemos elaborar um outro projeto, seguindo este mesmo tema e que busque a identificação de conceitos, a partir do adoecer visto, agora, como um Acontecimento.

\section{RESUMO}

TELLES, F. S. P.; ANTOUN, H. \& ARÊAS, J. B. Doença e Tempo. Cad. Saúde Públ., Rio de Janeiro, 9 (3): 309-315, jul/set, 1993.

Trata-se de um ensaio que procura estabelecer a propriedade da questão: "Faz sentido conceber a doença como um fenômeno que transcende as categorias da representação?"

Destaca-se uma correspondência entre os fenômenos da representação e da espacialização. Representar passa a ser a atividade de definir uma trajetória que admite uma cronologia temporal de referência, onde um certo fenômeno é apresentado. O paradigma que define a "Anátomo-Clínica" e a Epidemiologia é considerado por nós como uma forma de representação ou espacialização da doença.

Conclui-se ser possível o acesso a algo que se denomina "adoecer", que transcende a representação "Anátomo-Clínica" e epidemiológica, desde que, para tal, se admita a possibilidade de o conhecimento poder ser, também, construído fora do espaço, isto é, no tempo não-cronológico.

Palavras-Chave: Fatores de Tempo; Doença; Filosofia Médica 


\section{REFERÊNCIAS BIBLIOGRÁFICAS}

BERGSON, H., 1990. Matéria e Memória. Rio de Janeiro: Martins Fontes.

DELEUZE, G., 1974. Lógica do Sentido. São Paulo: Perspectiva. , 1987. Proust e os Signos. Rio de Janeiro: Forense Universitária. , 1988. Diferença e Repetição. Rio de Janeiro: Graal. , 1988. Foucault. São Paulo: Brasiliense. 1990. A Imagem-Tempo - Cinema II.
, 1991. A Dobra - Leibniz e o Barro-

co. Campinas: Papirus.

DELEUZE, G. \& GUATTARI, F., 1992. 0 que é a Filosofia? Rio de Janeiro: Ed. 34.

DELEUZE, G., 1991. Bergsonism. New York: Zone Books.

FOUCAULT, M., 1987. O Nascimento da Clínica. Rio de Janeiro: Forense Universitária.

MACHADO, R., 1990. Deleuze e a Filosofia. Rio de Janeiro: Graal.

PORFIRIO, O. F., 1965. Isagoge - Introdução às Categorias de A ristóteles. São Paulo: Matese.

São Paulo: Brasiliense. 